\title{
European Society of Gastrointestinal Endoscopy (ESGE) curricula development for postgraduate training in advanced endoscopic procedures: rationale and methodology
}

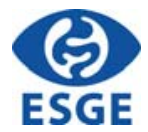

Authors

Raf Bisschops ${ }^{1}$, Evelien Dekker ${ }^{2}$, James E. East ${ }^{3,4}$, Gavin Johnson ${ }^{5}$, Pedro Pimentel-Nunes ${ }^{6,7,8}$, David S. Sanders ${ }^{9}$, Mario Dinis-Ribeiro ${ }^{6,7}$, Thierry Ponchon ${ }^{10}$

Institutions

1 Department of Gastroenterology and Hepatology, University Hospitals Leuven, and TARGID, KU Leuven, Leuven, Belgium

2 Department of Gastroenterology and Hepatology, Academic Medical Center, Amsterdam, The Netherlands

3 Translational Gastroenterology Unit, Nuffield Department of Medicine, Experimental Medicine Division, John Radcliffe Hospital, University of Oxford, Oxford, UK

4 Oxford NIHR Biomedical Research Centre, Oxford, UK

5 University College London Hospitals, London, UK

6 Gastroenterology Department, Portuguese Oncology Institute of Porto, Porto, Portugal

7 Center for research in health technologies and information systems (CINTESIS), Faculty of Medicine, University of Porto, Porto, Portugal

8 Surgery and Physiology Department, Faculty of Medicine of the University of Porto, Porto, Portugal

9 Academic Unit of Gastroenterology, Royal Hallamshire Hospital, Sheffield, UK

10 Gastroenterology Division, Edouard Herriot Hospital, Lyon, France

Bibliography

DOI https://doi.org/10.1055/a-1000-5603

Endoscopy 2019; 51: 976-979

(c) Georg Thieme Verlag KG Stuttgart · New York

ISSN 0013-726X

Corresponding author

Raf Bisschops, MD, PhD, Department of Gastroenterology and Hepatology, University Hospital Leuven, KU Leuven, Herestraat 49, 3000 Leuven, Belgium

Fax: +32-16-344225

raf.bisschops@uzleuven.be

\section{The challenge of postgraduate training in endoscopy}

Because of the accelerated development of new diagnostic and therapeutic techniques, qualified and certified endoscopists are confronted with new challenges in terms of achieving competence and providing up-to-date safe patient care in gastrointestinal endoscopy. Indeed, most standard curricula for endoscopy training during a gastroenterology or surgical fellowship do not cover new diagnostic or therapeutic techniques.

In addition, some older techniques like endoscopic retrograde cholangiopancreatography (ERCP) have become more difficult to learn owing to a shift from being formerly a diagnostic intervention to now being a solely therapeutic intervention,

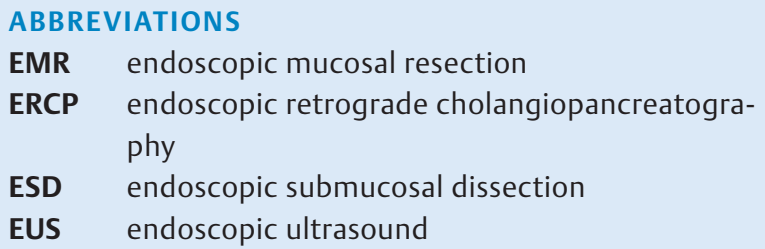

with increasing levels of technical difficulty when combined with interventional endoscopic ultrasound (EUS). Indeed, a generation of endoscopists who had the opportunity to obtain lots of experience in improving their cannulation rates, one of the key performance measures for ERCP [1], is now slowly retir- 
ing and the next generation is confronted with more complex cases earlier in their career. Because of the shift to therapeutic ERCP and the inherent potential complications, this is not included as standard in the core curriculum of gastrointestinal fellows in many countries.

Furthermore, there seems to be continuously increasing demand for interventional therapeutic endoscopy, which has in itself become more complex with the introduction of new and more invasive procedures (peroral endoscopic myotomy, endoscopic submucosal dissection [ESD], and combined EUS and ERCP for hepatobiliary interventions, among others). This in turn will increase the demand for more human resources in interventional endoscopy, all of whom need to be properly trained.

ESGE has in the past embraced quality in endoscopy as one of the main themes to put on the agenda in order to provide the highest quality of endoscopic care to our patients [2]. Evidently, the quality of the delivered patient care will be directly related to the technical and cognitive skills of the endoscopist. As a consequence, the quality of endoscopy is correlated with the quality of training.

\section{The importance of curricula}

Major challenges need to be met in order to compose a training curriculum. Acquiring the skills to perform advanced therapeutic endoscopy requires technical training but also cognitive understanding of the indications, complications, limitations, and therapeutic alternatives. It is clear that numbers of procedures are insufficient to guarantee technical competence in an advanced procedure. Indeed, in a recent systematic review, it was shown that studies exploring threshold numbers to reach competence in colonoscopy and ERCP vary significantly. More promise lies in the development and evaluation of assessment tools, which have been developed for some basic endoscopic procedures such as colonoscopy [3]. Assessment forms, like for instance the British Direct Observation of Procedural Skills (DOPS) or the Mayo Colonoscopy Skills Assessment Tool (MCSAT), are more effective in discriminating different experience levels and can be used in training settings [4, 5].

In addition, a simulator-based colonoscopy training on its own lacks the discriminative power to assess performance and competence levels in real-life patient-based endoscopy [3]. This implies that patient-based learning curves are in fact both a reality and a necessity for training, and that patients will be exposed to potential harm by endoscopists who are as yet relatively inexperienced in the procedure. In order to overcome this, in general, a stepwise introduction is proposed for interventional endoscopy. For instance, ASGE has proposed a 3-step grading scale for complexity in biliary and pancreatic ERCP procedures. When a certain threshold in the learning curve of the endoscopist is reached, more complex procedures can be introduced into the training program [6].

Despite the challenging nature of training in complex procedures and the large variation in learning curves, a systematic approach with standardized assessment using for instance “The EUS and ERCP Skills Assessment Tool" (TEESAT) has been proven to work when determining whether an advanced endos- copy trainee has the cognitive and technical competence to perform a procedure. Moreover, this translates into achievement of the key performance measures during the first year of independent practice $[7,8]$. For some advanced endoscopic procedures, training in animal models may have a significant additional ethical value: it allows the endoscopist to become acquainted with different devices and the basic techniques without any risk to patients [9]. This has offered a significant improvement in the technical aspects of ESD, for instance in the porcine pig colon [10].

In addition, prior to engaging in endoscopic resection of neoplastic lesions by ESD or endoscopic mucosal resection (EMR), additional training in optical diagnosis to increase detection and characterization skills is mandatory. Indeed, endoscopists need to achieve the skill of identifying macroscopic morphological features and combine this with advanced imaging to identify the features that may indicate deep submucosal invasion and exclude a curative endoscopic resection [11, 12]. This can probably be achieved with a minimum of effort by standardized training programs. Indeed, it has been shown that, if endoscopists participating in a colorectal cancer screening program are trained in optical diagnosis with a validated training module, they achieve a high negative predictive value for neoplastic lesions of $>90 \%$ and can achieve a surveillance interval that is in concordance with histology in $95 \%$ of cases. Interestingly, there is no significant difference whether or not there is regular interim feedback to the endoscopist $[13,14]$. These modules can be made available online, like for instance the BORN module, a well-developed and properly validated web-based educational tool, which clearly improves endoscopists' skills in detecting and delineating Barrett's lesions [15].

\section{Initial process}

In 2017, the ESGE board initiated the Curricula Working Group in order to develop curricula giving minimum standards and training for specific endoscopic procedures that are more interventional or advanced and, in general, require additional training beyond the core curriculum provided in each country. The aim is not to address a generic and general endoscopic training curriculum for fellows in endoscopy training. This is mostly defined by, and falls under the legal responsibility and authority of, the national accreditation bodies and may differ throughout the different European member states.

\section{Curricula working group}

The ESGE Curricula Working Group comprises a chair, and working group members who are appointed by the chair after ESGE Governing Board approval. They include members of the ESGE and, in selected cases, representatives of other medical or nonmedical societies. The list of current members is published on the ESGE website. The main tasks of the Curricula Working Group are to propose topics for new curricula and to participate in their detailed preparation. The Chair manages potential conflicts of interest and ensures that all of the curricula are scientifically sound, based on a thorough review of the literature, and are developed by a consensus process. 


\section{Selection of topics}

The chair and the members of the Curricula Working Group will propose the advanced techniques that potentially need to be covered. After searching for any existing up-to-date curricula on the proposed topics, the chair will present the proposed topics to the ESGE Governing Board, which will select and prioritize them. Criteria for the selection will include the clinical relevance of the advanced technique, the complexity of the training, and the potential to improve and assess outcomes.

As a first step, in 2017 we initiated the curriculum working groups for ESD (the resulting position statement is published in this issue [16]), optical diagnosis, and small-bowel endoscopy. In 2019, a working group on ERCP and interventional EUS was additionally instigated. We anticipate activating additional working groups for diagnostic EUS, endoluminal treatment of esophageal neoplasia, and EMR of laterally spreading tumors in the colon.

\section{Selection of working group members}

For each curriculum, a specific working group is formed. It generally involves around 10 members, including a leader. All groups are composed of candidates who are selected by the working group leader and curriculum chair after a call for participants from the ESGE. The ESGE will not provide honoraria to members of the working group but it will support administrative and meeting costs, including organization and the travel and accommodation cost of participants.

\section{Methodology for the development of a curriculum}

\section{Definition of training end points}

All groups are initiated with a face-to-face meeting to explain the methodology. As a first step, all working groups will define specific endpoints and thresholds for proficiency and competence in the different steps and aspects of training ( $\vee$ Table $\mathbf{1}$ ).

\section{Review of the evidence}

The working group will develop a list of key questions to support the assessment of technical and cognitive competence, (validated) training modules and assessment scales, and minimum requirements of trainers or training centers, according to the PICO (population, intervention, comparison, and outcome) format. A formal literature search will be conducted through Medline (via PubMed) and Google for any available evidence. In the next step, the literature search will be summarized and evidence graded according to the Grading of Recommendations Assessment, Development and Evaluation (GRADE) system [17].

\section{Statement development and consensus}

In order to define the different aspects of training, statements will be formulated based on the evidence and further developed through internal discussions within the working groups through teleconferencing or face-to-face meetings. These
- Table 1 Structure and content of ESGE postgraduate curricula.

\begin{tabular}{|l|l|}
\hline Section & Description \\
\hline Pre-adoption & $\begin{array}{l}\text { This section defines the skills and competence } \\
\text { that are necessary prior to engaging in the } \\
\text { advanced technique }\end{array}$ \\
\hline Training & $\begin{array}{l}\text { This section describes the different steps to } \\
\text { acquire competence in the different aspects of } \\
\text { the advanced technique; it also includes and } \\
\text { specifies the prerequisites for training modules } \\
\text { and training centers }\end{array}$ \\
\hline $\begin{array}{l}\text { Autonomous } \\
\text { implementation } \\
\text { and assessment } \\
\text { of proficiency }\end{array}$ & $\begin{array}{l}\text { This section describes the prerequisites, specific } \\
\text { numbers or certificates that need to be obtained, } \\
\text { and conditions for implementation of the } \\
\text { advanced technique independently in the } \\
\text { trainee's center }\end{array}$ \\
\hline
\end{tabular}

statements will form the basis for the construction of the curriculum. Agreement on the statements will be achieved through a modified Delphi process. For the latter, at least 10 additional experts will be invited to vote on each statement. Statements will be accepted if an agreement of $80 \%$ is reached after at least three Delphi voting rounds. After each voting round, comments and remarks generated during the Delphi process will be discussed to adjust the statements. This entire process will be conducted online and be entirely traceable.

\section{Structure of the curriculum}

Each working group will write a position statement manuscript that will be distributed for review to ESGE members. A structured abstract of no more than 300 words should be provided, with the main recommendations for training. The main text should contain the different sections listed in $>$ Table 1 . In a final step, the working groups will be instructed to create a trainee log book for the specific postgraduate training, based on the consensus reached in the Delphi process.

\section{Peer review and publication}

The peer review process for ESGE policy documents will be followed: two peer reviewers will be chosen from the ESGE Governing Board; these peer reviewers will be notified 1 month before the manuscript is submitted to ensure that the peer review process takes no more than 2 weeks. If the required expertise is not available amongst ESGE Governing Board members, peer review will be sought from outside of the ESGE Governing Board. The document will also be circulated to all national society members and ESGE individual members for feedback. All ESGE curricula documents will be made freely available on the ESGE website, in addition to being published in the journal Endoscopy.

\section{Conclusion and future prospects}

ESGE has a vision to create a thriving community of endoscopy services and endoscopists in Europe, to provide a high quality of care that is patient-centered [2]. The ESGE curricula initiative 
fits entirely within this framework. The curricula that will be produced in the next 2 years are the first step and an effort to harmonize training in advanced endoscopy with the aim of setting a standard for all endoscopists in Europe before engaging independently in these new interventional therapies, in order to provide safe treatments to patients. After finalization of the curricula, further collaboration with the ESGE educational committee and e-learning working group will be necessary to provide ESGE-endorsed training modules. Eventually, instigation of ESGE certification for certain aspects of advanced training could be the ultimate goal for our endoscopy society.

\section{Disclaimer}

ESGE Guidelines and Position Statements represent a consensus of best practice based on the available evidence at the time of preparation. They might not apply in all situations and should be interpreted in the light of specific clinical situations and resource availability. Further controlled clinical studies may be needed to clarify aspects of these statements, and revision may be necessary as new data appear. Clinical considerations may justify a course of action at variance with these recommendations.

ESGE Guidelines and Position Statements are intended to be an educational device providing information that may assist endoscopists in providing care to patients. They are not rules and should not be construed as establishing a legal standard of care or as encouraging, advocating, requiring, or discouraging any particular treatment.

\section{Acknowledgments}

R. Bisschops is supported by the Research Foundation - Flanders (FWO). J. E. East was funded by the National Institute for Health Research (NIHR) Oxford Biomedical Research Centre. The views expressed are those of the author(s) and not necessarily those of the National Health Service, the NIHR, or the Department of Health.

\section{Competing interests}

\footnotetext{
R. Bisschops has received research support from Cook and Medtronic, and financial support for symposium organization from Cook, Boston Scientific, Olympus, and Erbe (2009-2109), and speakers' fees from Boston Scientific and Medtronic (2009-2019). E. Dekker has received speaker's fees from Olympus, Roche, and GI Supply, has provided consultancy to FujiFilm, Olympus, Tillots, GI Supply, and CPP-FAP, and is a member of the supervisory board of eNose; she receives a research grant from FujiFilm (2017 to present). M. Dinis-Ribeiro is co-editor in-chief of Endoscopy. J. E. East received speaker's fees from Olympus and Falk (2018) and is on the clinical advisory boards of Boston Scientific and Lumendi (2016 to present). G. Johnson has served on advisory boards for Boston Scientific and Olympus (2017) and Medtronic (2018), and has been a faculty member for annual training courses supported by Olympus (2014 to present) and Boston Scientific (2017 to present). P. Pimentel-Nunes, T. Ponchon, and D. S. Sanders have no competing interests
}

\section{References}

[1] Domagk D, Oppong K, Aabakken L et al. Performance measures for ERCP and endoscopic ultrasound: a European Society of Gastrointestinal Endoscopy (ESGE) Quality Improvement Initiative. Endoscopy 2018; 50: $1116-1127$

[2] Rutter MD, Senore C, Bisschops R et al. The European Society of Gastrointestinal Endoscopy Quality Improvement Initiative: developing performance measures. Endoscopy 2016; 48: 81-89

[3] Ekkelenkamp VE, Koch AD, de Man RA et al. Training and competence assessment in $\mathrm{Gl}$ endoscopy: a systematic review. Gut 2016; 65: $607-$ 601

[4] Barton JR, Corbett S, van der Vleuten CP. The validity and reliability of a Direct Observation of Procedural Skills assessment tool: assessing colonoscopic skills of senior endoscopists. Gastrointest Endosc 2012; 75: $591-597$

[5] Sedlack RE. The Mayo Colonoscopy Skills Assessment Tool: validation of a unique instrument to assess colonoscopy skills in trainees. Gastrointest Endosc 2010; 72: 1125-1133.e3

[6] ASGE training committee. Jorgensen J, Kubiliun $\mathrm{N}$ et al. Endoscopic retrograde cholangiopancreatography (ERCP): core curriculum. Gastrointest Endosc 2016; 83: 279-289

[7] Wani S, Keswani RN, Petersen B et al. Training in EUS and ERCP: standardizing methods to assess competence. Gastrointest Endosc 2018; 87: $1371-1382$

[8] Wani S, Hall M, Wang AY et al. Variation in learning curves and competence for ERCP among advanced endoscopy trainees by using Cumulative sum analysis. Gastrointest Endosc 2016; 83: 711-719.e11

[9] Herreros De Tejada A. ESD training: A challenging path to excellence. World J Gastrointest Endosc 2014; 6: 112-120

[10] Gromski MA, Cohen J, Saito K et al. Learning colorectal endoscopic submucosal dissection: a prospective learning curve study using a novel ex vivo simulator. Surg Endosc 2017; 31: 4231 - 4237

[11] Burgess NG, Hourigan LF, Zanati SA et al. Risk stratification for covert invasive cancer among patients referred for colonic endoscopic mucosal resection: a large multicenter cohort. Gastroenterology 2017; 153: $732-742 . e 1$

[12] Puig I, López-Cerón M, Arnau A et al. Accuracy of the Narrow-Band Imaging International Colorectal Endoscopic Classification System in identification of deep invasion in colorectal polyps. Gastroenterology 2019; 156: 75-87

[13] McGill S, Soetikno R, Rastogi A et al. Endoscopists can sustain high performance for the optical diagnosis of colorectal polyps following standardized and continued training. Endoscopy 2014; 47: 200-206

[14] Vleugels JLA, Dijkgraaf MGW, Hazewinkel Y et al. Effects of training and feedback on accuracy of predicting rectosigmoid neoplastic lesions and selection of surveillance intervals by endoscopists performing optical diagnosis of diminutive polyps. Gastroenterology 2018; 154: 1682 - 1693.e1

[15] Bergman JJGHM, de Groof AJ, Pech O et al. An interactive web-based educational tool improves detection and delineation of Barrett's esophagus-related neoplasia. Gastroenterology 2019; 156: 12991308.e3

[16] Pimentel-Nunes P, Pioche M, Albéniz E et al. Curriculum for endoscopic submucosal dissection training in Europe: European Society of Gastrointestinal Endoscopy (ESGE) position statement. Endoscopy 2019; 51: 980 - 992

[17] Atkins D, Best D, Briss PA et al. Grading quality of evidence and strength of recommendations. BMJ 2004; 328: 1490 


\section{CORRECTION}

Bisschops R, Dekker E, East JE et al. European Society of Gastrointestinal Endoscopy (ESGE) curricula development for postgraduate training in advanced endoscopic procedures: rationale and methodology.

Endoscopy 51; 2019: 976-979.

In the above-mentioned article, the name of the author Pedro Pimentel-Nunes has been corrected. This was corrected in the online version on October 25, 2019 